\title{
Modelling, Design and Analysis of Car Bonnet Assembly - Simulation Results \& Discussions
}

\author{
Dileep P ${ }^{1}$, Shivappa H.A ${ }^{2}$, Preethi $K^{3}$, Chandan $\mathbf{R}^{4}$, Byregowda K.C. ${ }^{5}$ \\ ${ }^{1}$ Student M Tech, MMD, Department of Mechanical Engineering, Dr Ambedkar Inst. of Tech., Bengaluru - 56 \\ ${ }^{2,3,4,5}$ Assistant Professors, Department of Mechanical Engineering, Dr Ambedkar Inst. of Tech., Bengaluru - 56
}

\begin{abstract}
In this paper, the Modelling, Design and Analysis of Car Bonnet Assembly with the Simulation Results is presented in brief along with the justifications that are being carried out.
\end{abstract}

Keywords: Car Bonnet, structural analysis, CATIA V5 R20, Hypermesh, MSc NASTRAN, Simulation Results.

\section{INTRODUCTION}

Car bonnet is the important component which is utilized for several purposes at the front. It gives access to the engine compartment which enable the repair and maintenance of many parts namely car engine, radiator etc. Therefore, bonnet must be designed in suitable manner and it should minimize the hindrances from the disturbance caused by the external environment on the hood and its components below it. When the car is in running condition, the resisting forces from the air acting on the hood therefore the design of the bonnet should be made aerodynamic to reduce the air resistance. Hood assembly includes inner panel, outer panel, hinges, latch and reinforcements. The upper and stiffener panels are joined through the process of hemming or both panels are joined by using the adhesive namely mastic. Spot weld can be made where it will be necessary. Sandwich construction of the hood structure that will increases the capability of the hood's ability to absorb the energy impacted by the external forces which are acting on the bonnet. The bonnets of the most vehicles are basically fabricated using the sheet metal structure, a good energy absorbing structure so it causes substantially a small threat.

Outer and inner stiffener panels are made or fabricated by using the of sheet metal structures therefore environment used is surface modelling. Since the hood assembly is a sheet metal component, hood structure is vulnerable to the vibrations. The source of the vibrations could be the engine generated vibrations, the vibrations due to the un-evenness in the road surface, and aerodynamic interactions of the hood surface when the vehicle is in motion. Excessive vibrations will put an impact on the passenger's ride comfort, and also make the structure susceptible to fatigue failure. Too many vibrations also affect the functioning of the locking mechanism of the bonnet, considerably risking the unlocking function and bonnet will be open up while the vehicle is in motion. Because of the many ongoing efforts are to reduce the weight of the vehicle, the thickness of the bonnet is being reduced to its possible values. This could considerably increase the severity of the vibrations that the structure is subjected to. Hence, determining the fundamental frequencies of the bonnet structure and its behaviour at those frequencies is necessary.

\section{SIMULATIONS CARRIED OUT}

Simulation are carried out using the software tool Nastran. Bonnet is one of the main important components of a car at the front portion used to decorate the car and to add luxurious look. The shape of the bonnet is to be made aerodynamic in order to minimize the drag. Bonnet is used as a shield/cover to access the parts such as radiator, engine and many other components, hence the design is made in such away so that it can be easily accessible. In this project work, different materials were used for the same bonnet design and ultimately arrived at a conclusion for the stiffest bonnet. The static structural analysis is carried out on engine hood to evaluate the stresses and displacements induced in the car bonnet assembly for two different materials and the obtained results were interpreted. For designing the hood, geometric model was created using CATIA V5 R20, 3D modeler and then CAD model was imported into Hypermesh for meshing. The static and modal analysis was carried out for bonnet assembly using NASTRAN. The obtained results were viewed using Hyperview.

Here, the simulation results for the oil canning case is being present for the Steel AISI 1045 50N Load case. The Fig. 1 gives the displacement Plot for 50N load, whereas the Fig. 2 gives the graphical display of the results w.r.t. the Von mises stress plot for $50 \mathrm{~N}$ load, from which we can come to a conclusion that as the load increases, the performance also increases. 


\section{International Advanced Research Journal in Science, Engineering and Technology}

Vol. 8, Issue 12, December 2021

DOI: $10.17148 /$ IARJSET.2021.81240

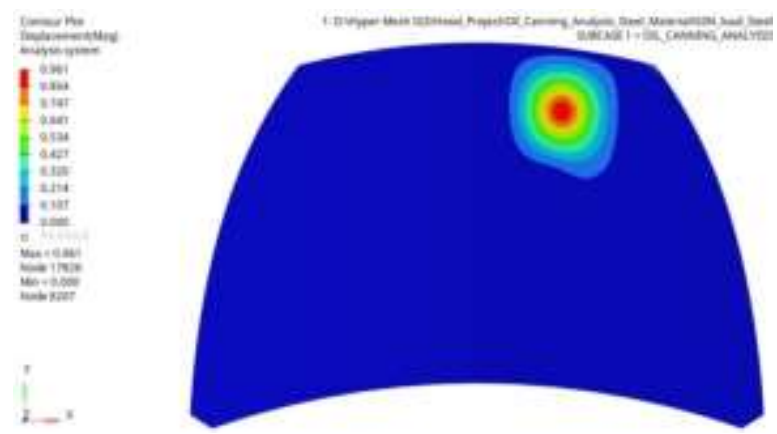

Fig. 1 : Displacement Plot for 50N load

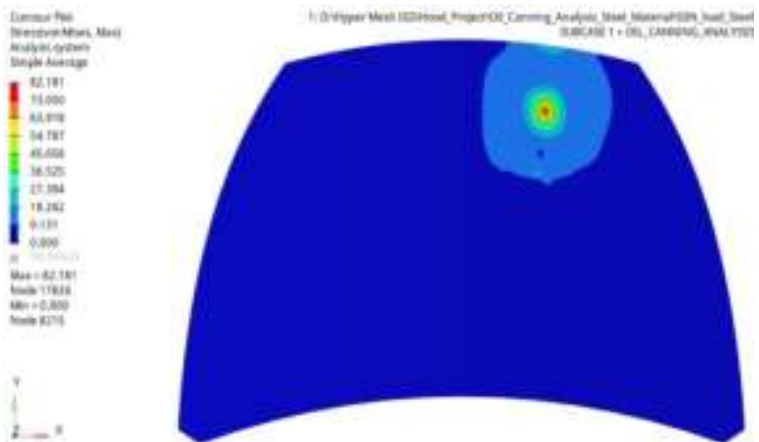

Fig. 2 : Von mises stress plot for $50 \mathrm{~N}$ load

Here, the simulation results for the oil canning case is being present for the Steel AISI 1045 100N Load case. The Fig. 3 gives the displacement Plot for 100N load, whereas the Fig. 4 gives the simulated results for the Von mises stress plot for $100 \mathrm{~N}$ load, from which we can come to a conclusion that as the load increases, the performance also increases.
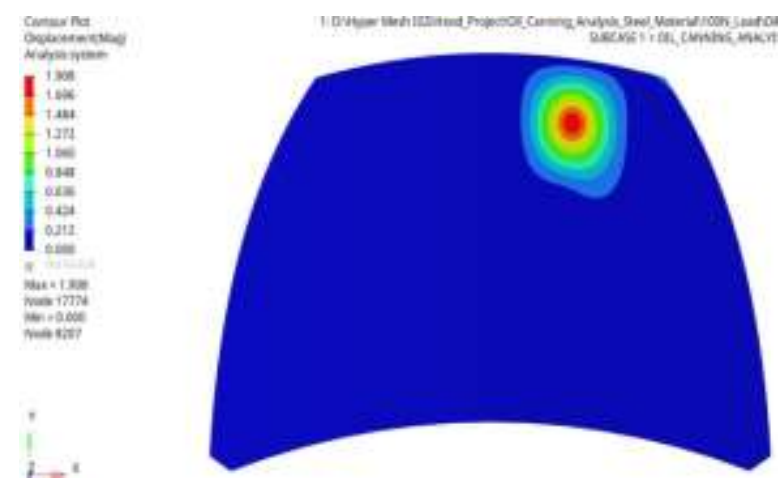

Fig. 3 : Displacement Plot for $100 \mathrm{~N}$ load

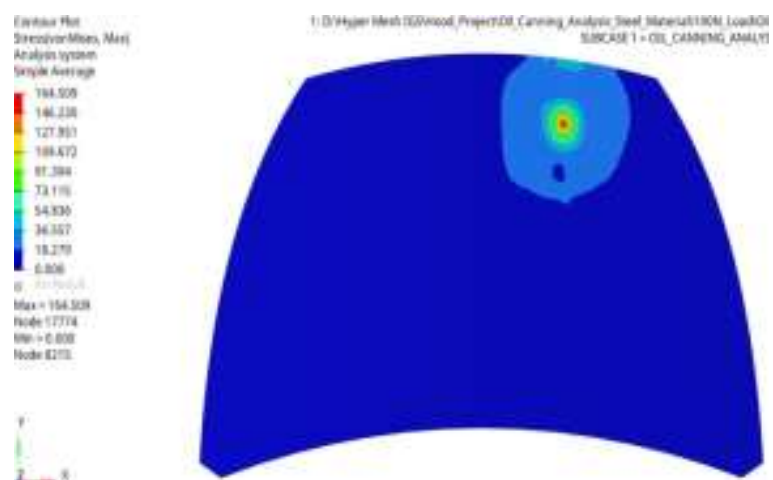

Fig. 4 : Von mises stress plot for 100N load

Now, we consider for an aluminium 6061 composite material case for different types of loads. First, we consider the Aluminium 6061 case. For a $50 \mathrm{~N}$ load case, we consider the following and get the simulated results. The Fig. 5 gives 


\section{International Advanced Research Journal in Science, Engineering and Technology}

Vol. 8, Issue 12, December 2021

\section{DOI: 10.17148/IARJSET.2021.81240}

the displacement Plot for 50N load, whereas the Fig. 6 gives the results for a Von mises stress plot for 50N load. The Fig. 7 gives the displacement Plot for 100N load, whereas the Fig. 8 gives the simulated results for a Von mises stress plot for $100 \mathrm{~N}$ load, from which we can come to a conclusion that as the load increases, the performance also increases.

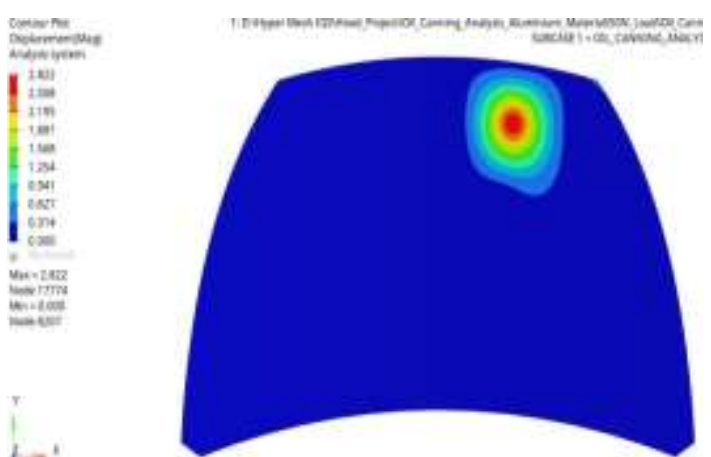

Fig. 5 : Displacement Plot for 50N load

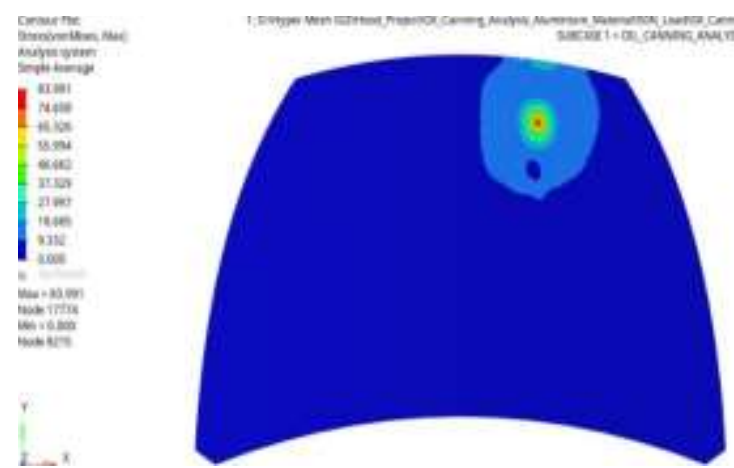

Fig. 6 : Von mises stress plot for $50 \mathrm{~N}$ load

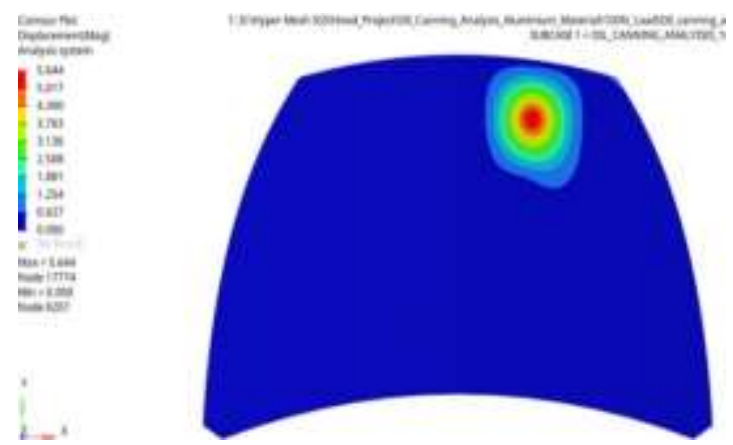

Fig. 7 : Displacement Plot for 100N load

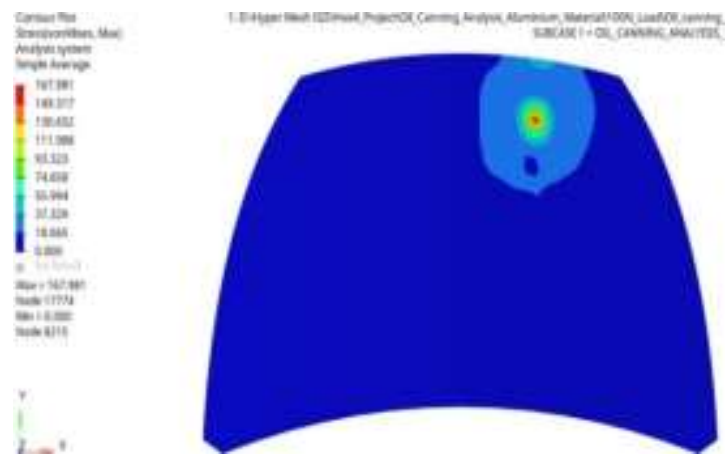

Fig. 8 : Von mises stress plot for $100 \mathrm{~N}$ load

Here, the simulation results for the oil canning case is being present for the Torsional Stiffness analysis for a 50N Load case \& a $100 \mathrm{~N}$ load case. The Fig. 9 gives the displacement Plot for 50N load, whereas the Fig. 10 gives the graphical display of the results w.r.t. the Von mises stress plot for $50 \mathrm{~N}$ load, from which we can come to a conclusion that as the 


\section{International Advanced Research Journal in Science, Engineering and Technology}

Vol. 8, Issue 12, December 2021

\section{DOI: 10.17148/IARJSET.2021.81240}

load increases, the performance also increases. The Fig. 11 gives the displacement Plot for 50N load, whereas the Fig. 12 gives the results for a Von mises stress plot for $50 \mathrm{~N}$ load.
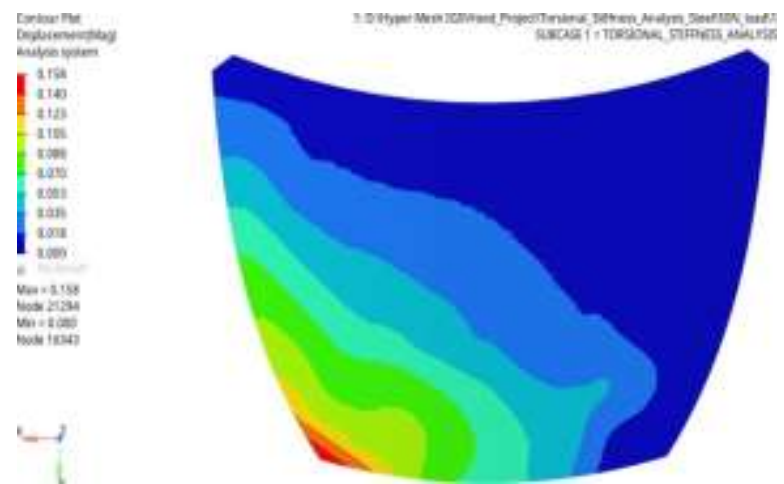

Fig. 9 : Displacement Plot for 100N load
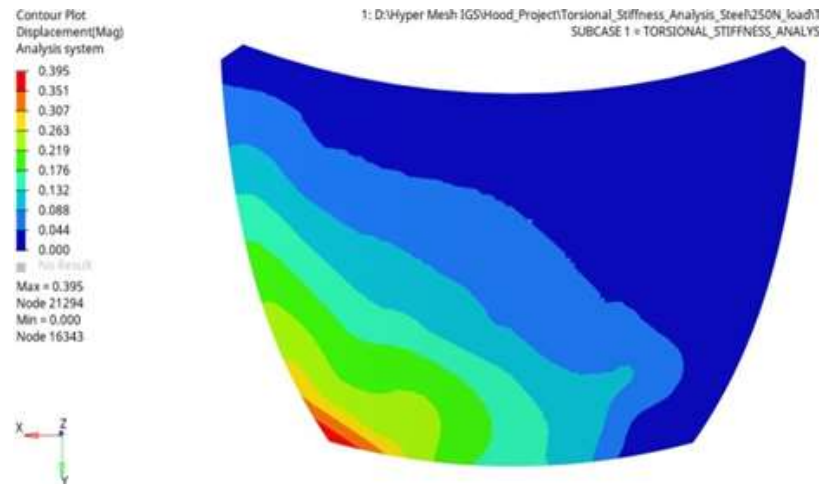

Fig. 10 : Displacement Plot for 250N load
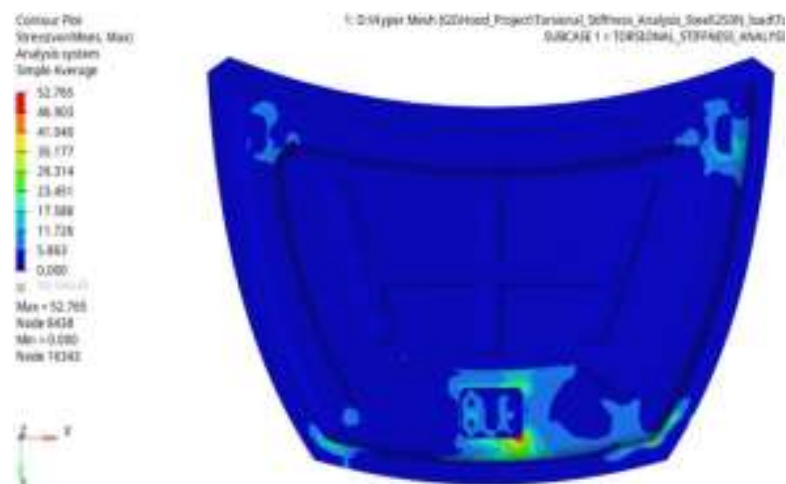

Fig. 11 : Von mises stress plot for $250 \mathrm{~N}$ load

Here, the simulation results for the oil canning case is being present for the aluminum composite material for a $50 \mathrm{~N}$ Load case \& a $100 \mathrm{~N}$ load case. The Fig. 12 gives the displacement Plot for 50N load, whereas the Fig. 13 gives the graphical display of the results w.r.t. the Von mises stress plot for $50 \mathrm{~N}$ load, from which we can come to a conclusion that as the load increases, the performance also increases. The Fig. 14 gives the displacement Plot for $250 \mathrm{~N}$ load, whereas the Fig. 15 gives the results for a Von mises stress plot for $250 \mathrm{~N}$ load. 
International Advanced Research Journal in Science, Engineering and Technology

Vol. 8, Issue 12, December 2021

DOI: $10.17148 /$ IARJSET.2021.81240

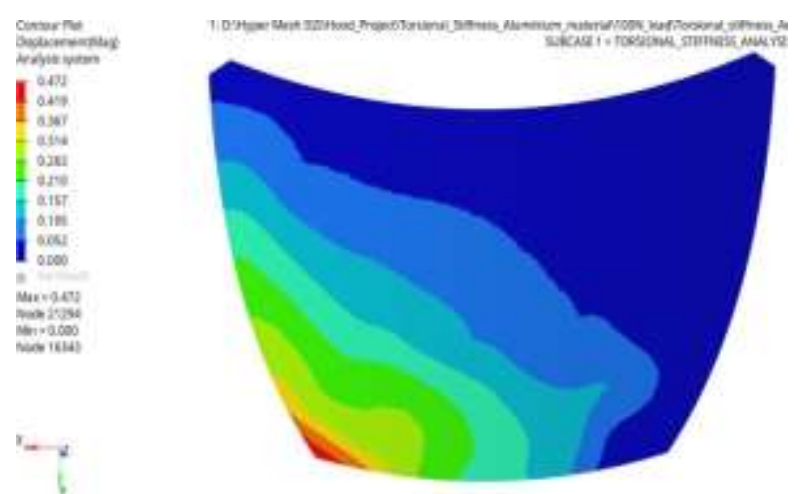

Fig. 12 : Displacement Plot for 100N load

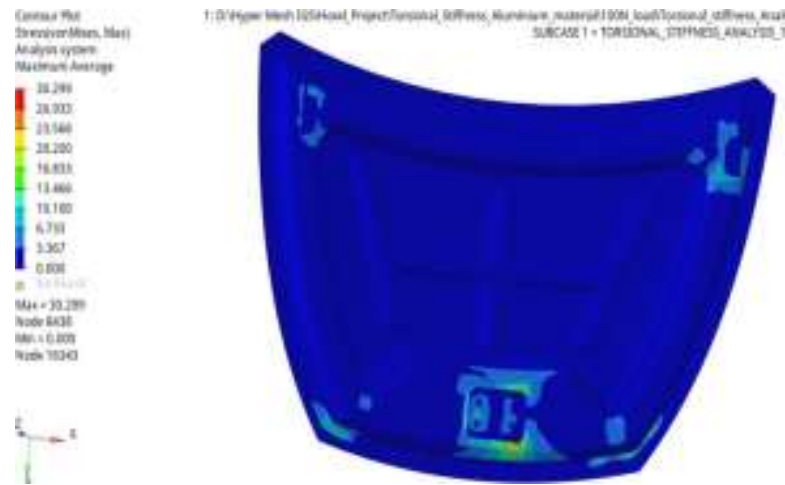

Fig. 13 : Von mises stress plot for $100 \mathrm{~N}$ load

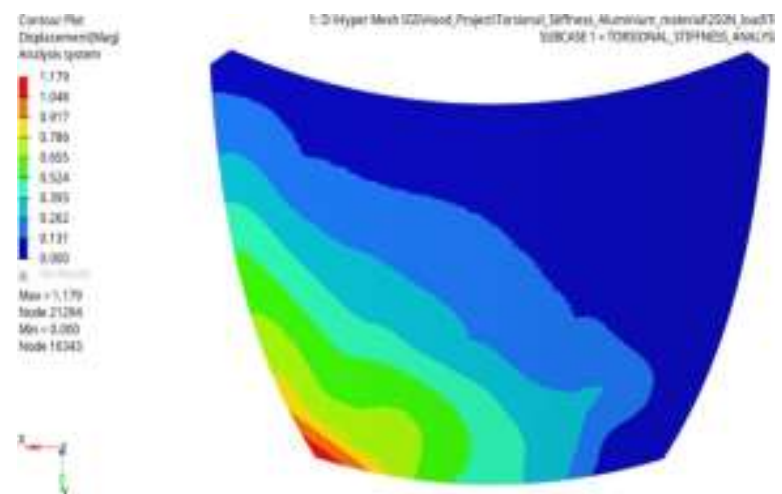

Fig. 14 : Displacement Plot for 250N load

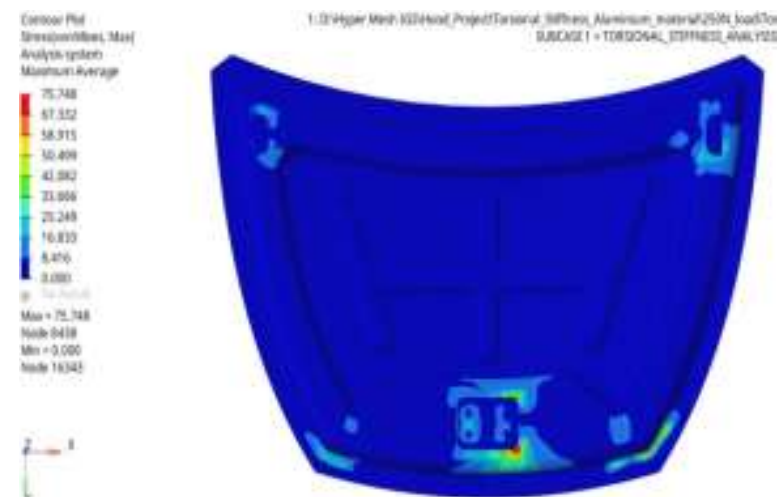

Fig. 15 : Von mises stress plot for 250N load

Here, the simulation results for the oil canning case is being present for the modal analysis for different types of loads cases, say $50 \mathrm{~N}, 100 \mathrm{~N}, 250 \mathrm{~N}$, etc... Fig. 16 gives the simulation results for Mode 7 at $68.09 \mathrm{~Hz}$, whereas the Fig. 17 


\section{International Advanced Research Journal in Science, Engineering and Technology}

Vol. 8, Issue 12, December 2021

\section{DOI: $10.17148 /$ IARJSET.2021.81240}

gives the simulation results for Mode 8 at $98.63 \mathrm{~Hz}$. The Fig. 18 gives the simulation results for Mode 9 at $107.4 \mathrm{~Hz}$, whereas the Fig. 19 gives the simulation results for the Mode 10 at $111.3 \mathrm{~Hz}$. This is for the free case.
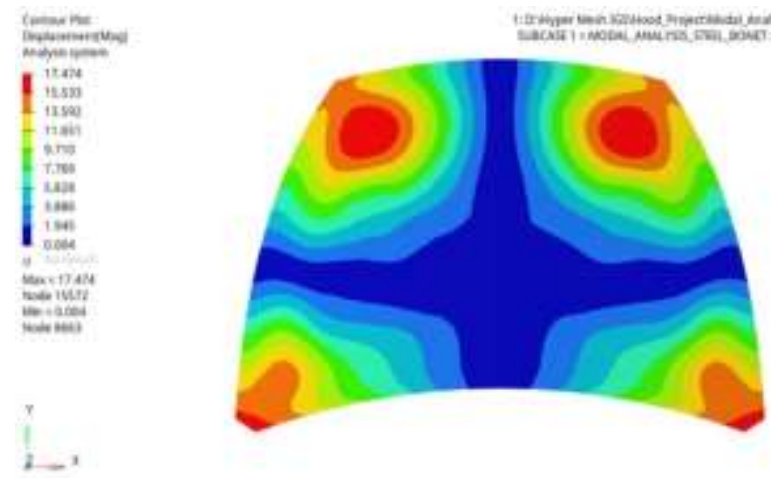

Fig. 16 : Mode 7 at $68.09 \mathrm{~Hz}$
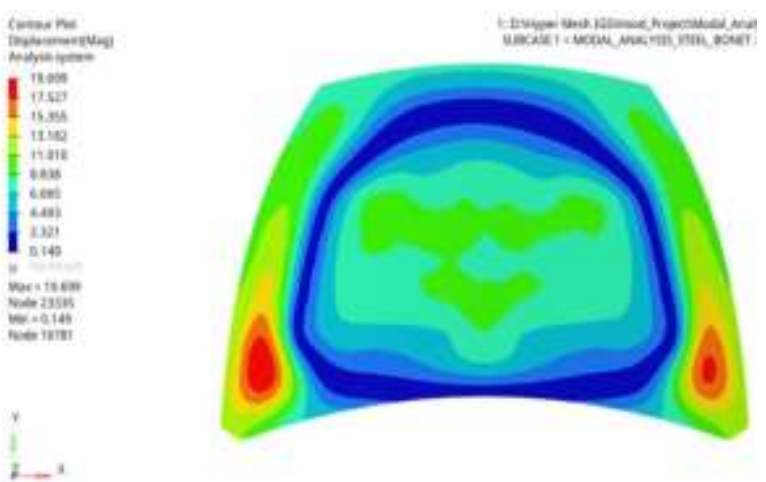

Fig. 17 : Mode 8 at $98.63 \mathrm{~Hz}$
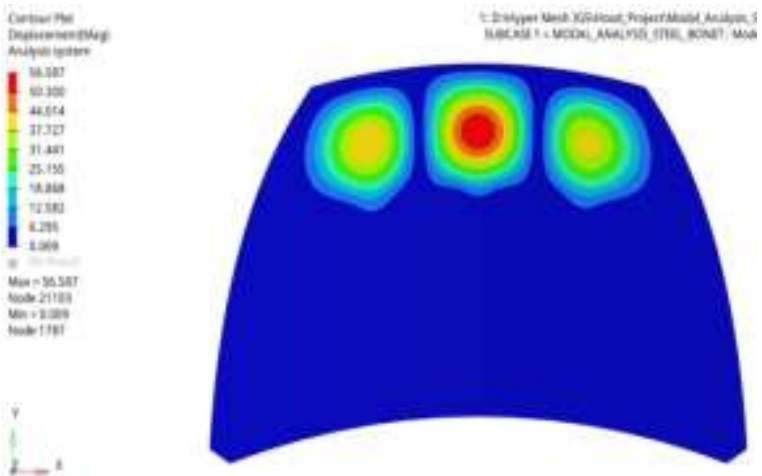

Fig. 18 : Mode 9 at $107.4 \mathrm{~Hz}$
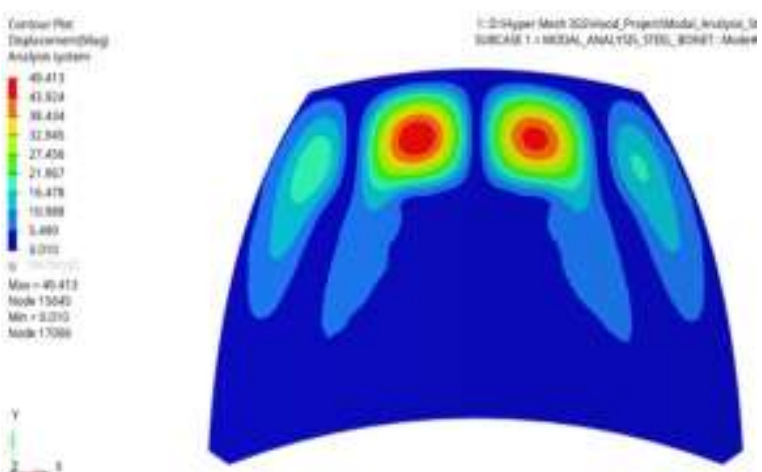

Fig. 19 : Mode 10 at $111.3 \mathrm{~Hz}$ 


\section{International Advanced Research Journal in Science, Engineering and Technology}

Vol. 8, Issue 12, December 2021

\section{DOI: 10.17148/IARJSET.2021.81240}

Here, the simulation results for the oil canning case is being present for the modal analysis for different types of loads cases, say $50 \mathrm{~N}, 100 \mathrm{~N}, 250 \mathrm{~N}$ and different frequencies, etc... Fig. 20 gives the simulation results for the Mode 6 at $135.9 \mathrm{~Hz}$, whereas the Fig. 21 gives the simulation results for the Mode 7 at $153.4 \mathrm{~Hz}$. The Fig. 22 gives the simulation results for Mode 8 at $154.5 \mathrm{~Hz}$, whereas the Fig. 23 gives the simulation results for the Mode 9 at $162.1 \mathrm{~Hz}$. Finally, the Fig. 24 gives the simulation results for the Mode 10 at $165.8 \mathrm{~Hz}$.
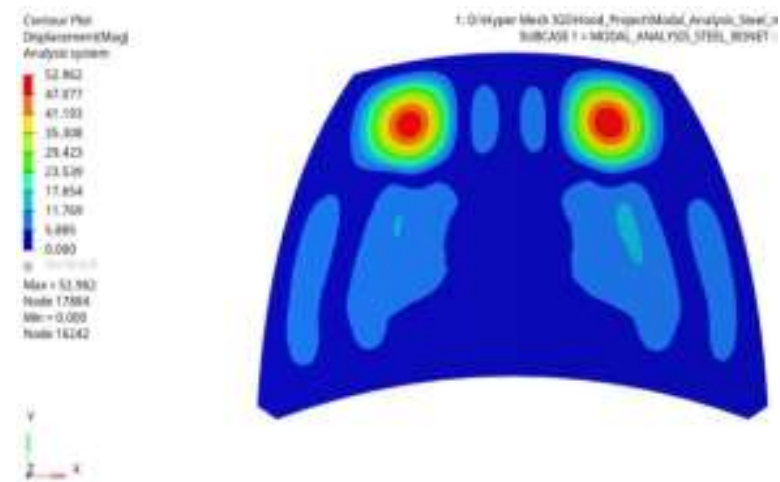

Fig. 20 : Mode 6 at $135.9 \mathrm{~Hz}$
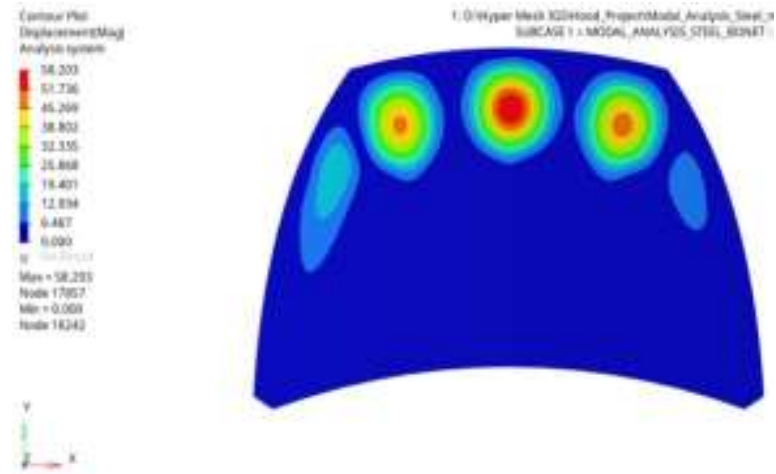

Fig. 21 : Mode 7 at $153.4 \mathrm{~Hz}$
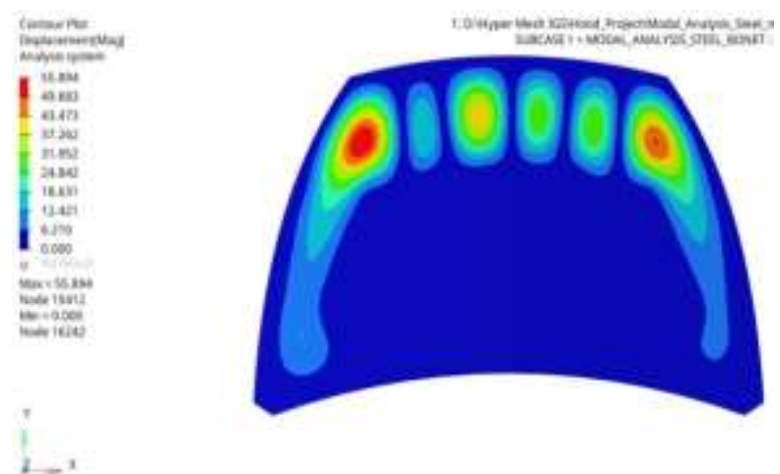

Fig. 22 : Mode 8 at $154.5 \mathrm{~Hz}$ 


\section{International Advanced Research Journal in Science, Engineering and Technology}

Vol. 8, Issue 12, December 2021

DOI: $10.17148 /$ IARJSET.2021.81240
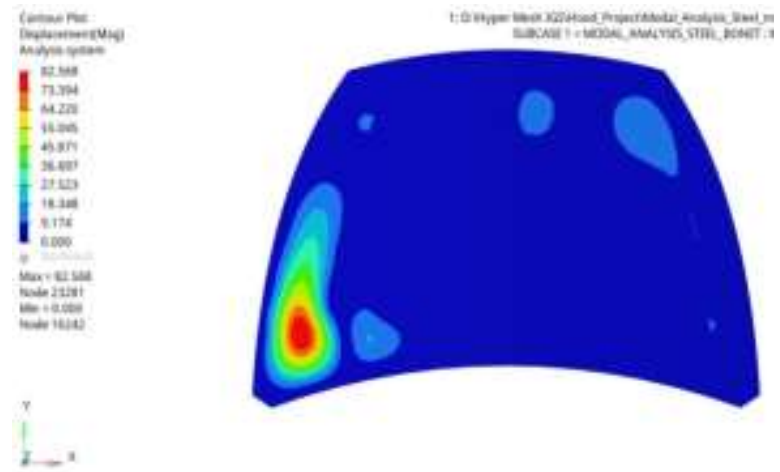

Fig. 23 : Mode 9 at $162.1 \mathrm{~Hz}$
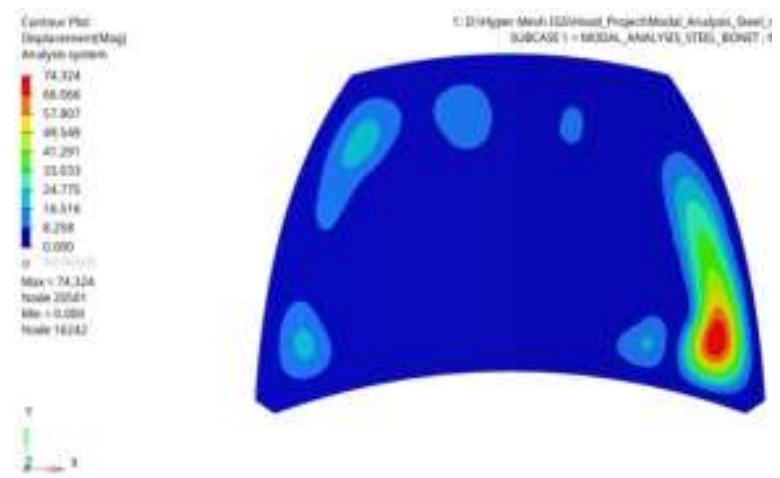

Fig. 24 : Mode 10 at $165.8 \mathrm{~Hz}$

Here, the simulation results for the oil canning case is being present for the modal analysis for different types of frequencies, etc... for free to free vibrational conditions. Fig. 25 gives the simulation results for the Mode $7 \mathrm{at} 67.37 \mathrm{~Hz}$, whereas the Fig. 26 gives the simulation results for the Mode 8 at 97.90Hz. Similarly, the Fig. 27 gives the simulation results for the Mode 9 at $106.7 \mathrm{~Hz}$ and the Fig. 28 gives the simulation results for the Mode 10 at $110.6 \mathrm{~Hz}$. From these simulation results, we can come to a conclusion that as the frequencies increases the performance also increases.
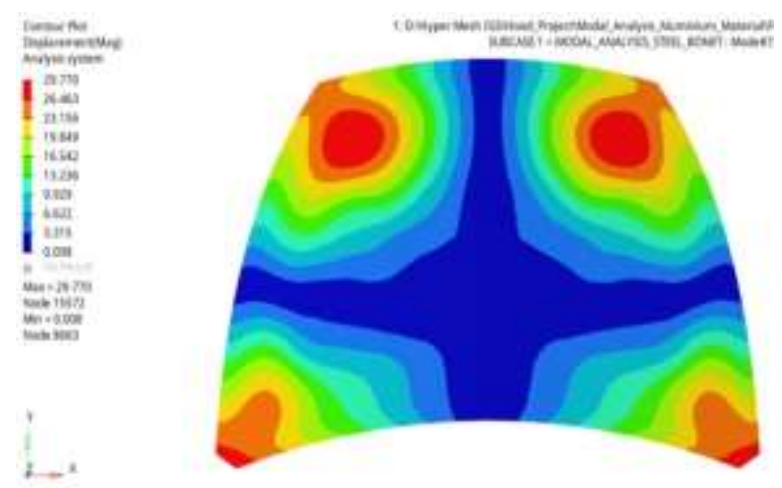

Fig. 25 : Mode 7 at $67.37 \mathrm{~Hz}$ 


\section{International Advanced Research Journal in Science, Engineering and Technology}

Vol. 8, Issue 12, December 2021

DOI: $10.17148 /$ IARJSET.2021.81240
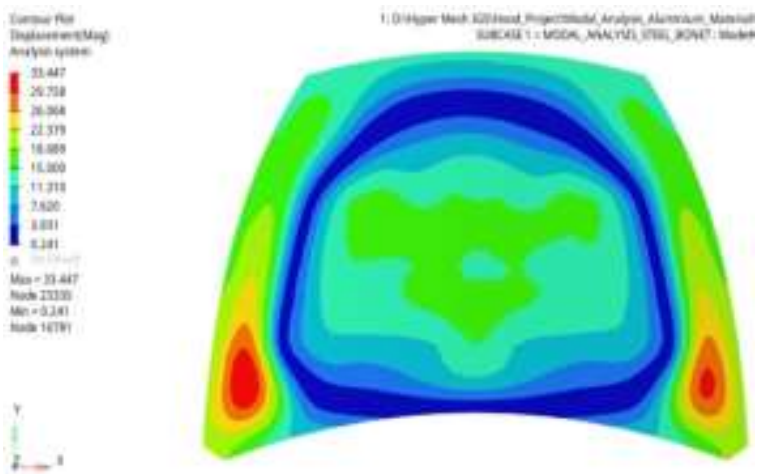

Fig. 26 : Mode 8 at $97.90 \mathrm{~Hz}$
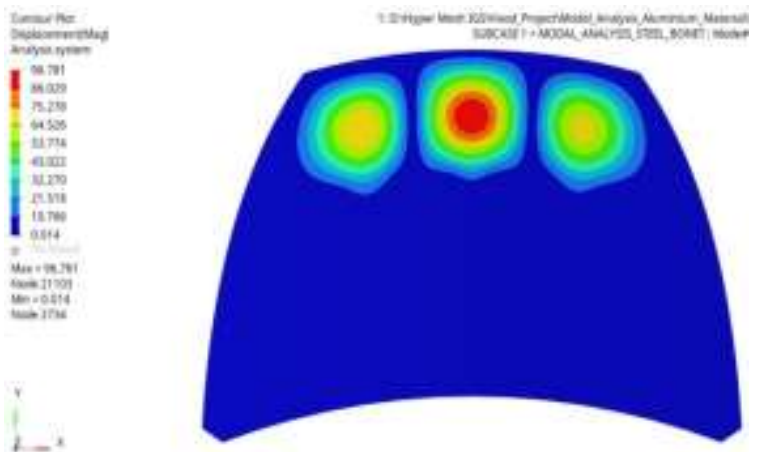

Fig. 27 : Mode 9 at $106.7 \mathrm{~Hz}$
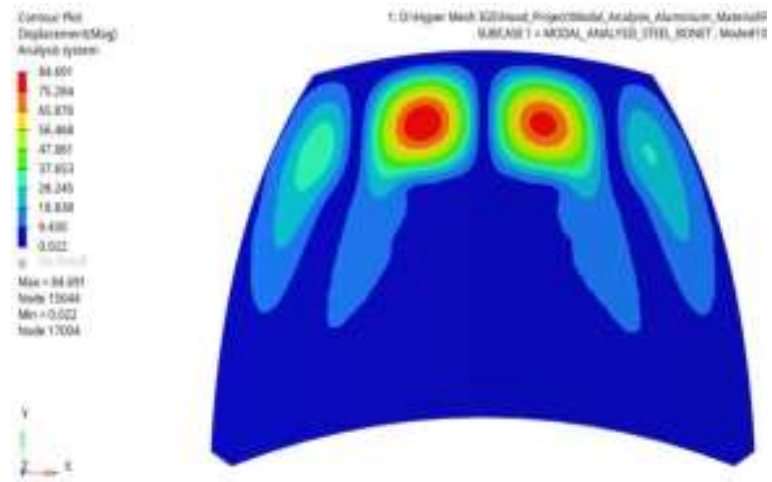

Fig. 28 : Mode 10 at $110.6 \mathrm{~Hz}$

Here, the simulation results for the oil canning case is being present for the modal analysis for different types of frequencies, etc... for fixed vibrational conditions. The Fig. 29 gives the simulation results for the Mode 7 at $152.3 \mathrm{~Hz}$, whereas the Fig. 30 gives the simulation results for the Mode 8 at $153.8 \mathrm{~Hz}$. Similarly, the Fig. No. 31 gives the simulation results for the Mode 9 at $161.3 \mathrm{~Hz}$, whereas the Fig. 32 gives the simulation results for the Mode 10 at $165.0 \mathrm{~Hz}$. From these simulation results, we can come to a conclusion that as the frequencies increases the performance also increases. 


\section{International Advanced Research Journal in Science, Engineering and Technology}

Vol. 8, Issue 12, December 2021

DOI: $10.17148 / I A R J S E T .2021 .81240$
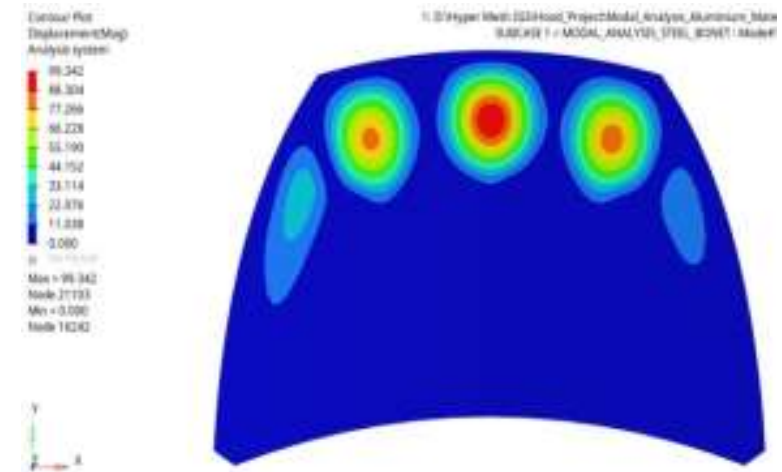

Fig. 29 : Mode 7 at $152.3 \mathrm{~Hz}$
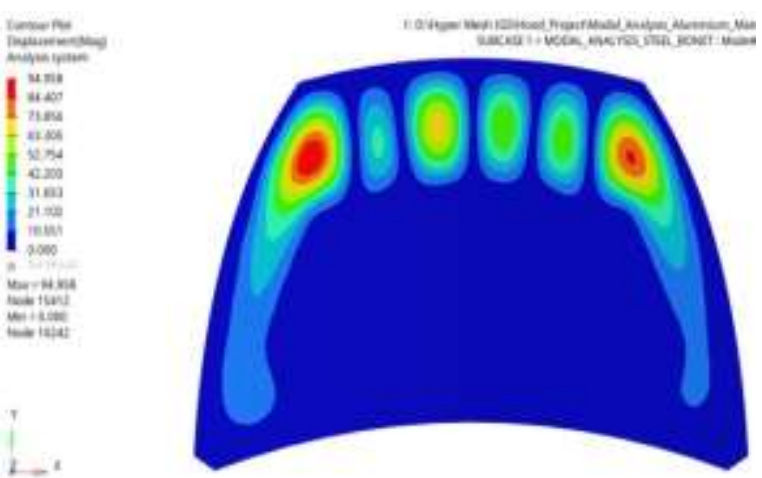

Fig. 30 : Mode 8 at $153.8 \mathrm{~Hz}$
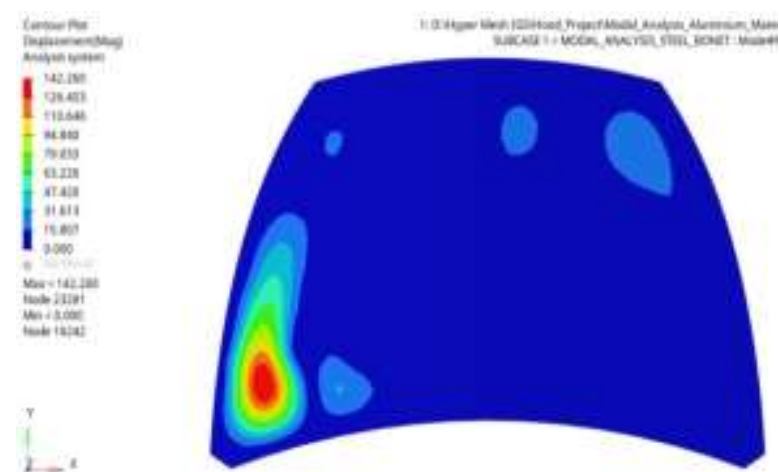

Fig. 31 : Mode 9 at $161.3 \mathrm{~Hz}$
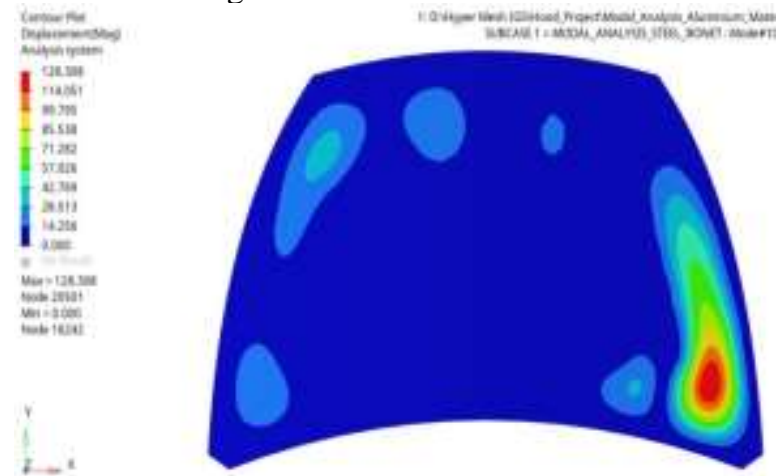

Fig. 32 : Mode 10 at $165.0 \mathrm{~Hz}$

Next, we present the quantitative results for the oil canning case is being present for the modal analysis for different types of frequencies, for different types of loads etc... in the form of tabulations shown in different tables from Tables 1 to 16 respectively. These quantitative results are used to plot the excel plots. 
International Advanced Research Journal in Science, Engineering and Technology

Vol. 8, Issue 12, December 2021

DOI: $10.17148 / I A R J S E T .2021 .81240$

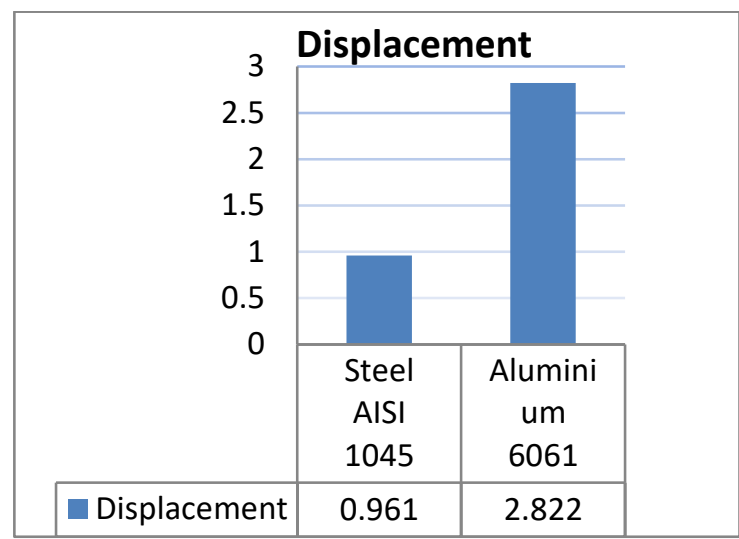

Table 1 : Displacement comparison of oil canning for $50 \mathrm{~N}$

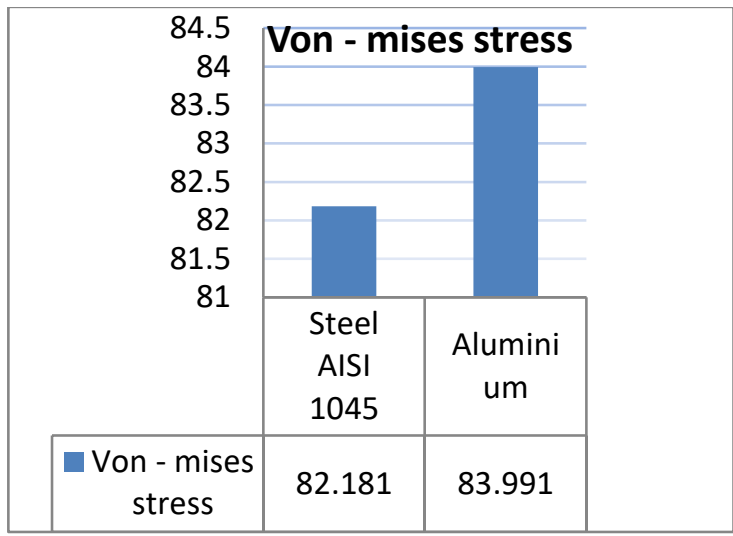

Table 2 : Von-mises stress plot for $50 \mathrm{~N}$

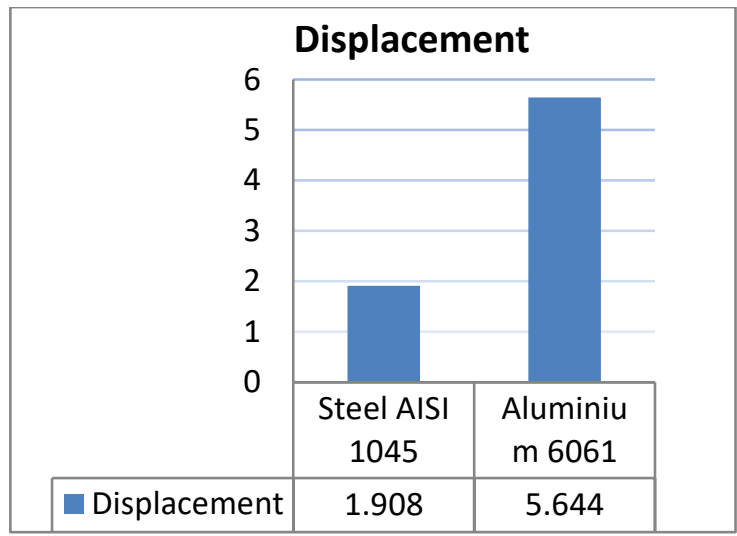

Table 3 : Displacement comparison of oil canning for $100 \mathrm{~N}$ for steel $\&$ aluminium case 
International Advanced Research Journal in Science, Engineering and Technology

Vol. 8, Issue 12, December 2021

DOI: $10.17148 / I A R J S E T .2021 .81240$

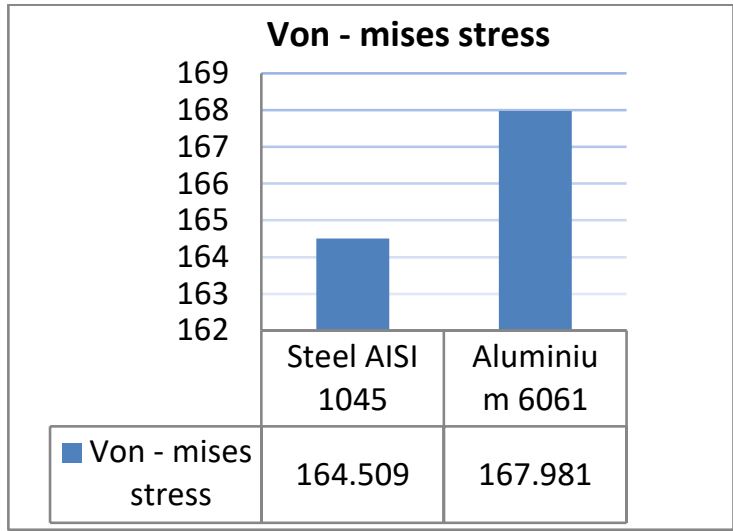

Table 4 : Stress comparison of oil canning for $100 \mathrm{~N}$

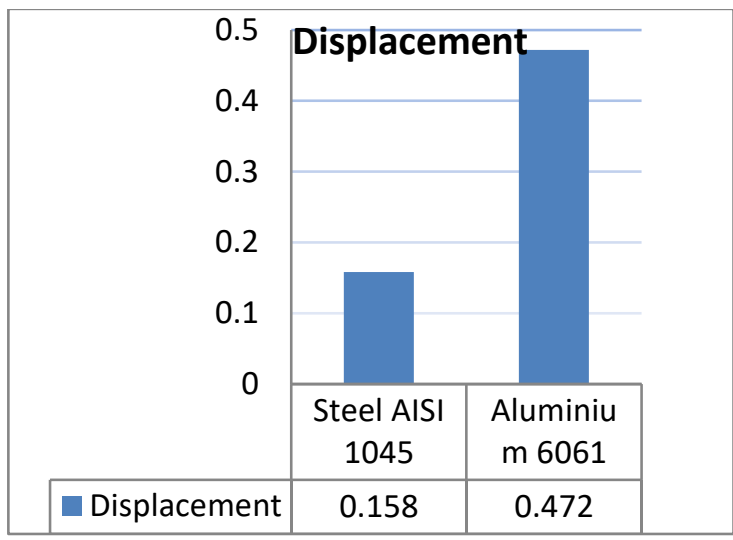

Table 5 : Displacement comparison of Torsional stiffness analysis for $100 \mathrm{~N}$

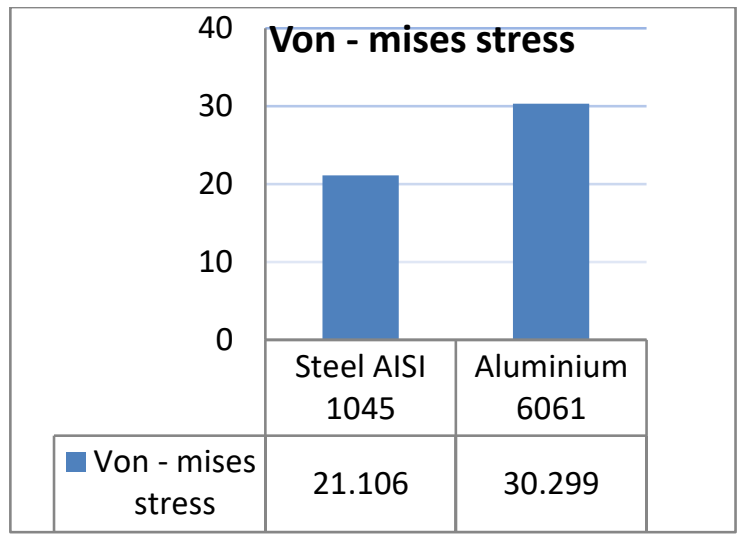

Table 6 : Stress comparison of Torsional stiffness analysis for $100 \mathrm{~N}$ 
International Advanced Research Journal in Science, Engineering and Technology

Vol. 8, Issue 12, December 2021

DOI: $10.17148 / I A R J S E T .2021 .81240$

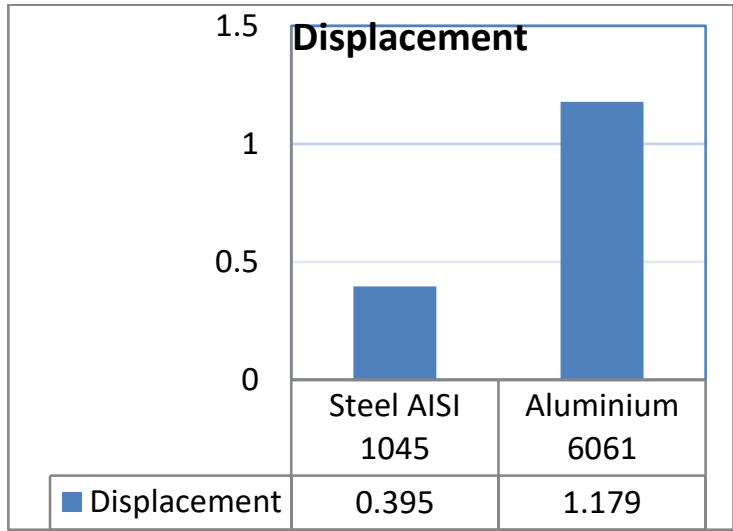

Table 7 : Displacement comparison of Torsional stiffness analysis for $250 \mathrm{~N}$

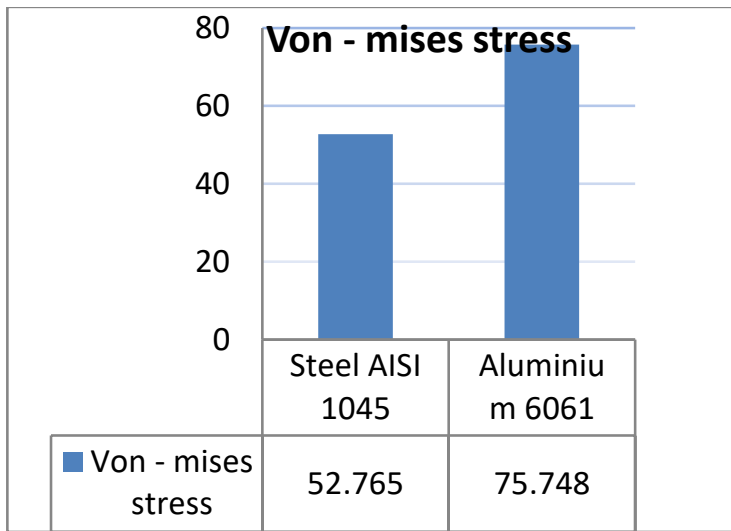

Table 8 : Stress comparison of Torsional stiffness analysis for $250 \mathrm{~N}$

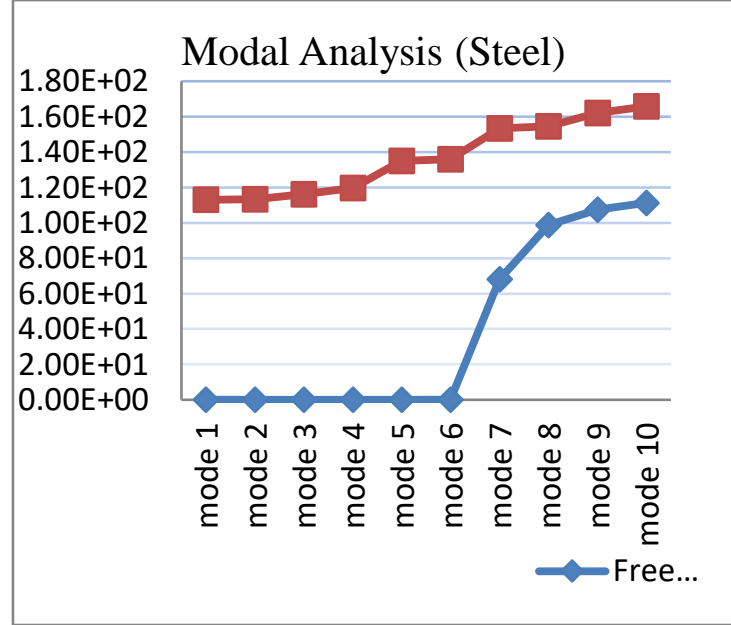

Table 9 : Results for Modal Analysis (Steel) 


\section{International Advanced Research Journal in Science, Engineering and Technology}

Vol. 8, Issue 12, December 2021

DOI: $10.17148 /$ IARJSET.2021.81240

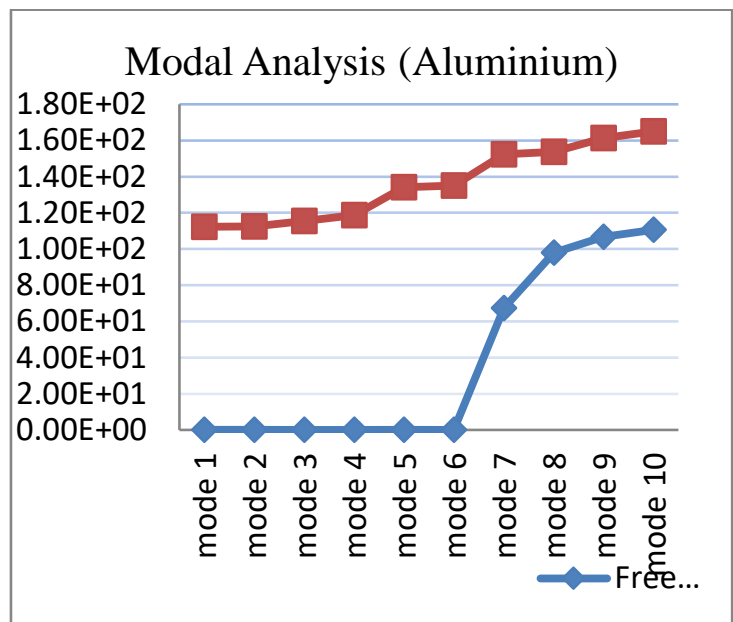

Table 10 : Results for Modal Analysis (Aluminium)

Now, we present the overall comparative statement results for 2 types of materials, viz., Steel \& Aluminum case with the quantitative results, from which the performance for the AL case is brighter because of the lighter in weight. Note that this is for the oil canning case.

\begin{tabular}{|l|l|l|l|l|}
\hline Sl no. & Material & Load case & Displacement in $(\mathrm{mm})$ & Von - mises stress in (Mpa) \\
\hline \multirow{2}{*}{1} & \multirow{2}{*}{ Steel AISI 1045 } & $50 \mathrm{~N}$ & 0.961 & 82.181 \\
\cline { 3 - 5 } & & $100 \mathrm{~N}$ & 1.908 & 164.509 \\
\hline \multirow{2}{*}{2} & \multirow{2}{*}{ Aluminium 6061 } & $50 \mathrm{~N}$ & 2.822 & 83.991 \\
\cline { 3 - 5 } & & $100 \mathrm{~N}$ & 5.644 & 167.981 \\
\hline
\end{tabular}

Table 11 : Oil canning case results

Now, we present the overall comparative statement results for 2 types of materials, viz., Steel \& Aluminum case with the quantitative results, from which the performance for the AL case is brighter because of the lighter in weight. Note that this is for the Torsional stiffness case.

\begin{tabular}{|l|l|l|l|l|}
\hline No. & Material & Load case & Displacement in $(\mathrm{mm})$ & Von - mises stress in (Mpa) \\
\hline \multirow{2}{*}{1} & \multirow{2}{*}{ Steel AISI 1045 } & $100 \mathrm{~N}$ & 0.158 & 21.106 \\
\cline { 3 - 5 } & & $250 \mathrm{~N}$ & 0.395 & 52.765 \\
\hline \multirow{2}{*}{2} & \multirow{2}{*}{ Aluminium 6061 } & $100 \mathrm{~N}$ & 0.472 & 30.299 \\
\cline { 3 - 5 } & & $250 \mathrm{~N}$ & 1.179 & 75.748 \\
\hline
\end{tabular}

Table 12 : Stiffness analysis case results

\begin{tabular}{|l|l|l|}
\hline Mode no. & Frequency in $\mathbf{( H z )}$ & Displacement in (mm) \\
\hline 1 & $2.427 \mathrm{e}-04$ & 14.950 \\
\hline 2 & $1.762 \mathrm{e}-04$ & 12.818 \\
\hline 3 & $1.491 \mathrm{e}-04$ & 11.868 \\
\hline 4 & $1.278 \mathrm{e}-04$ & 16.358 \\
\hline 5 & $8.141 \mathrm{e}-05$ & 14.297 \\
\hline 6 & $2.720 \mathrm{e}-04$ & 13.638 \\
\hline 7 & 68.09 & 17.474 \\
\hline 8 & 98.63 & 19.699 \\
\hline 9 & 107.4 & 56.587 \\
\hline 10 & 111.3 & 49.413 \\
\hline
\end{tabular}

Table 13 : Results of frequency in $\mathrm{hz} \mathrm{v} / \mathrm{s}$ displacement in $\mathrm{mm}$

Now, we present the simualtion resutls for the modal analysis case for steel AISI 1045 one for a free to free conditional case. Results of frequency in $\mathrm{hz} \mathrm{v/s}$ displacement in $\mathrm{mm}$ for free and fixed cases are also presented here w.r.t. the quantititaive numbers. Note that this for both $\mathrm{Al} \&$ steel case.

\section{\begin{tabular}{|l|l|l|}
\hline Mode no. & Frequency in $(\mathrm{Hz})$ & Displacement in $(\mathbf{m m})$ \\
\hline
\end{tabular}}


International Advanced Research Journal in Science, Engineering and Technology

Vol. 8, Issue 12, December 2021

DOI: $10.17148 /$ IARJSET.2021.81240

\begin{tabular}{|l|l|l|}
\hline 1 & 113.0 & 29.007 \\
\hline 2 & 113.4 & 33.304 \\
\hline 3 & 116.1 & 53.659 \\
\hline 4 & 119.6 & 55.874 \\
\hline 5 & 135.1 & 53.166 \\
\hline 6 & 135.9 & 52.962 \\
\hline 7 & 153.4 & 58.203 \\
\hline 8 & 154.5 & 55.894 \\
\hline 9 & 162.1 & 82.568 \\
\hline 10 & 165.8 & 74.324 \\
\hline
\end{tabular}

Table 14 : Results of frequency in $\mathrm{hz} \mathrm{v/s} \mathrm{displacement} \mathrm{in} \mathrm{mm}$ for steel

\begin{tabular}{|l|l|l|}
\hline Mode no. & Frequency in $\mathbf{( H z})$ & Displacement in $(\mathbf{m m})$ \\
\hline 1 & $2.114 \mathrm{e}-04$ & 21.287 \\
\hline 2 & $1.520 \mathrm{e}-04$ & 23.725 \\
\hline 3 & $7.142 \mathrm{e}-05$ & 20.282 \\
\hline 4 & $3.421 \mathrm{e}-05$ & 28.772 \\
\hline 5 & $8.882 \mathrm{e}-05$ & 24.077 \\
\hline 6 & $1.426 \mathrm{e}-05$ & 29.707 \\
\hline 7 & 67.37 & 29.770 \\
\hline 8 & 97.90 & 33.447 \\
\hline 9 & 106.7 & 96.781 \\
\hline 10 & 110.6 & 84.961 \\
\hline
\end{tabular}

Table 15 : Results of frequency in $\mathrm{hz} \mathrm{v} / \mathrm{s}$ displacement in $\mathrm{mm}$ for steel

\begin{tabular}{|l|l|l|}
\hline Mode no. & Frequency in $\mathbf{( H z})$ & Displacement in $(\mathbf{m m})$ \\
\hline 1 & 112.3 & 51.580 \\
\hline 2 & 112.6 & 59.839 \\
\hline 3 & 115.4 & 89.693 \\
\hline 4 & 118.8 & 95.086 \\
\hline 5 & 134.2 & 91.383 \\
\hline 6 & 135.0 & 90.203 \\
\hline 7 & 152.3 & 99.342 \\
\hline 8 & 153.8 & 94.958 \\
\hline 9 & 161.3 & 142.260 \\
\hline 10 & 165.0 & 128.308 \\
\hline
\end{tabular}

Table 16 : Results of frequency in $\mathrm{hz} \mathrm{v} / \mathrm{s}$ displacement in $\mathrm{mm}$ for $\mathrm{Al}$ case

\section{CONCLUSIVE REMARKS}

In this paper, the Modelling, Design and Analysis of Car Bonnet Assembly with the Simulation Results was presented in brief along with the justifications that are being carried out. For the Oil canning case, the following the final overall conclusive remarks. The values of Displacement obtained from the oil canning analysis for the steel material for both $50 \mathrm{~N}$ and $100 \mathrm{~N}$ are found to be lesser than the displacement values obtained for Aluminium. In the oil canning analysis the stress values developed in each of the material for two different loads are almost equal or There is no much difference in the stress values.

For the Torsional stiffness analysis, the following the final overall conclusive remarks. The values of Displacement obtained from the Torsional Stiffness analysis for the steel material for both $100 \mathrm{~N}$ and $250 \mathrm{~N}$ are found to be lesser than the displacement values obtained for Aluminium. In the Torsional Stiffness analysis the stress values developed in Steel are less compare to the stress values of Aluminum. Since the Deformation or Displacement values obtained from the analysis (i.e. oil canning and Torsional stiffness analysis) are less in Steel AISI 1045 compare to Aluminum 6061, the Bonnet design made of Steel is more stiff compare to the Bonnet design made of Aluminium. In oil canning analysis for both Steel AISI 1045 and Aluminium 6061, stress values are almost same and there is no much difference of 2 - $3 \%$ in the stress results. In Torsional Stiffness analysis for both Steel AISI 1045 and Aluminium 6061, stress reduction of $30.342 \%$ is found in the steel compare to the Aluminium. 


\section{International Advanced Research Journal in Science, Engineering and Technology}

Vol. 8, Issue 12, December 2021

DOI: $10.17148 /$ IARJSET.2021.81240

\section{REFERENCES}

[1]. D. Costi, E. Torricelli, L. Splendi and M. Pettazzoni, "Optimization Methodology for an Automotive Hood Substructure (Inner Panel)" in Proceedings of the World Congress on Engineering, Vol III, WCE 2011.

[2]. Mahesha J. and Prashanth A. S., "Design Verification Procedure (DVP) Load Case Analysis of Car Bonnet", International Advanced Research Journal in Science, Engg. and Tech., vol. 3, Issue 8, Aug. 2016, pp. 91-98.

[3]. N. Bhaskar and P. Rayudu, "Design and Analysis of a Car Bonnet", International Journal of Current Engineering and Technology, vol.5, No.5, Oct. 2015, pp. 3105-3109.

[4]. Rupesh Rodke, Dileep Korade "Design and Development of Passenger Car Hood using FEA" in IERJ, Special Issue 2, Page 2028-2033, 2015, ISNN 2395-1621

[5]. Rupesh Y. Bhagat, Amol P. More, “A Review: Analysis and Optimization of Car Bonnet” in IJIRD, Vol 3, Issue 1, January 2014

[6]. N. Bhaskar, P. Rayudu, "Design and Analysis of a Car Bonnet" in International Journal of Current Engineering and Technology, Vol.5, No.5, Oct 2015

[7]. Anand Vikram Singh, Jyothi Prasad Gooda, "Static and Impact Analysis of a Composite Engine Hood Assembly for Improved Characteristics" in Altair Technology Conference, 2015

[8]. D. Costi, E. Torricelli, L. Splendi and M. Pettazzoni, "Optimization Methodology for an Automotive Hood Substructure (Inner Panel)" in Proceedings of the World Congress on Engineering, Vol III, WCE 2011

[9]. Kiran Kausadikar, Pankaj Bhirud and Chetan Khadsare, "Optimization An Effective Tool in Bonnet Design cycle" in Altair Technology Conference, 2013

[10]. Ramesh C. K, Dr. Srikari S., Suman M. L. J(2012), Design of Hood Stiffener of a Sedan Car for Pedestrian Safety, SASTECH Journal, Volume 11

[11]. Masoumi A., Mohammad Hassan Shojaeefard and Amir Najibi.,(2010), Comparison of steel, aluminium and composite bonnet in terms of pedestrian head impact Automotive Engineering Department, Iran University of Science \& Technology, Iran.

[12]. Wu, J. P. and Beaudet(2007), Optimization of head impact waveform to minimize HIC, SAE Paper No. 2007-01- 0759.

[13]. Cheng, C.-S. and Wang, J. T(2002), An Analytical Study of Pedestrian Headform Impacts Using a Dual Asymmetrical Triangle Functionbl, GM R\&D Pu ication No. R\&D-9326, May 2002;

[14]. Akarsh S, March (2009), Design of a sedan bonnet to reduce pedestrian head injury, MSRSAS, Bangalore. Christian Pinecki, Richard Zeitouni(2007). Technical solutions for enhancing the pedestrian Protection Paper number 07-0307 